\section{Lowland Maya radiocarbon dates and the classic Maya collapse}

SIDRYS AND BERGER" assert that "the demise of the stela cult and the breakdown of elite culture seem to have coincided" among the Late Classic Maya population of the Southern Lowlands. Their evidence leans heavily on a comparison of frequency distribution graphs for long count-dated Maya monuments and radiocarbon-dated organic materials. The authors claim that the graphs are "remarkably similar", and that their resemblance "helps to establish the reliability of the ${ }^{14} \mathrm{C}$ frequency-distribution bar-graph method".

We feel that the radiocarbon data presented by Sidrys and Berger show such a bias in sampling that the conclusions they draw are unreliable and misleading. Of the 96 radiocarbon dates plotted for the elite contexts' (in contrast to 415 monument dates) 66 dates are from the site of Tikal-no other single site is represented by more than 5 dates. Since the authors are attempting to analyse a demographic phenomenon that took place over thousands of square kilometres and involved many population centres, we suggest that selecting nearly $70 \%$ of the samples from one site dangerously disregards basic tenets of sampling theory. To demonstrate the effect that such an extreme bias in the radiocarbon data can have on the interpretation made by the authors, we have replotted their frequency-distribution graph for elite contexts, specifically excluding the dates from Tikal. The dates from all of the other 26 sites and artefacts that are listed in their Table 1 have been left unchanged. For comparison we have also reproduced the authors' original graph, which includes the Tikal data.

The replotted data (Fig. 1b) fail to support any significant 'breakdown of elite culture' during the eighth to eleventh centuries $A D$ It is not our intention to question whether or not a breakdown actually took place. Our point is that such a drastic difference in interpretation, based solely on the presence or absence of data from a single site, renders spurious Sidrys and Berger's argument that a connection between the demise of the stela cult and the breakdown of elite culture is supported by a similarity between the frequency distribution of monument dates and elite context radiocarbon dates.

While we endorse the trend towards increasing quantification of archaeological data, particularly for the purpose of hypothesis testing, we emphasise that studies involving demography must take into account the need for representative sampling of available sites and contexts.

\section{STERNS}

C. LORIA

Department of Anthropology,

Cornell University,

Ithaca, New York 14853

\author{
R. GARBER \\ Section of Botany, Genetics and \\ Development, \\ Cornell University, \\ Ithaca, New York 14853
}

1. Sidrys, R. \& Berger, R. Nature 277, 269-274 (1979).

SIDRYS AND BERGER REPLY-OUI study did take into account the need for representative sampling of available sites. The high proportion of Tikal cases in our ${ }^{14} \mathrm{C}$ graph of elite contexts simply refiects the abnormally large number of aristocrats, priests and administrators present at Tikal-a factor that Sterns, Loria and Garber overlook. Population estimates for Classic Maya centres are difficult to obtain and their reliability may be off by at least a factor of two. Nonetheless, those
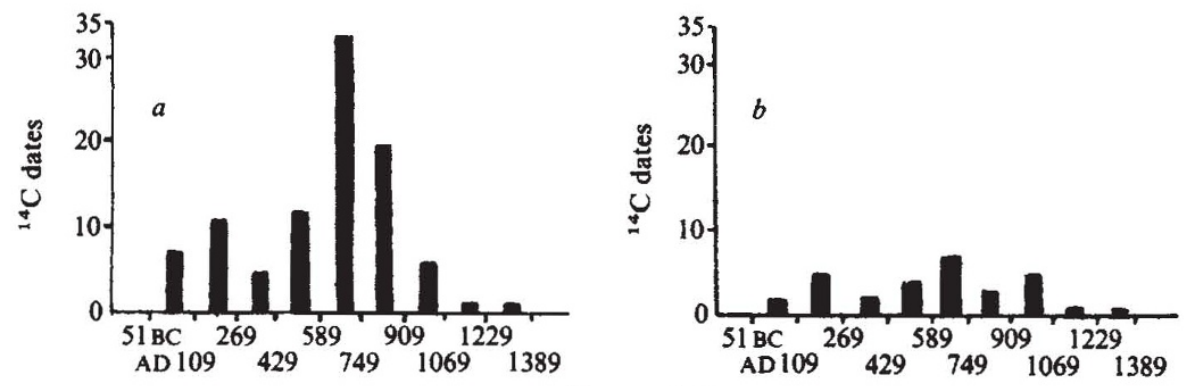

Time periods

Fig. $1 a$, Radiocarbon dates from elite contexts in the Southern Lowlands per time period, including dates from Tikal. $b$, The same data as in $a$, but excluding the dates from Tikal. studying the Mayan culture are in general agreement that Classic period Tikal was the largest population centre, with about 50,000 inhabitants ${ }^{1}$ (some estimates are as high as 80,000 ). The number of Tikal elite has been estimated ${ }^{2}$ to be 1,000 . In contrast the average population of the other 18 sites used in our Fig. $3 a$, according to our own 'guestimates' based on house mounds and size of ceremonial area, as well as the little published demographic data available, falls somewhere between 3,000 and 9,000.

Our sampling procedure thus mirrors Classic Maya cultural reality-the overwhelming economic and political dominance of the capital city of Tikal. Viewed from this perspective, the above graph by Sterns, Loria, and Garber that eliminates Tikal from the total elite sample is the equivalent of a demographic study of the state of New York that does not include New York City. At the same time, we do emphatically reiterate that more Maya ${ }^{14} \mathrm{C}$ dates from commoner contexts are urgently needed to resolve the issue of the Classic Maya collapse.

\section{RAYMOND SIDRYS} RAINER BERGER

Department of Anthropology, Geography and Institute of Geophysics, UCLA, California 90024

1. Haviland, W. World Archaeol. 2, 186-197 (1970)

2. Adams, R. E. W. in Mesoamerican Archeology (ed. Hammond, N.) (University of Texas Press, Austin, 1974).

\section{Matters Arising}

Matters Arising is meant as a vehicle for comment and discussion about papers that appear in Nature. The originator of a Matters Arising contribution should initially send his manuscript to the author of the original paper and both parties should, wherever possible, agree on what is to be submitted. Neither contribution nor reply (if one is necessary) should be longer than 300 words and the briefest of replies, to the effect that a point is taken, should be considered.

\section{$\mathrm{Ca}^{2+}$ and photoreceptor adaptation}

FLAMING AND BROWN ${ }^{1}$ seem to have missed the point of our earlier work on the effects of altered extracellular $\mathrm{Ca}^{2+}$ on rod photoreceptor responses ${ }^{2}$, and they give a misleading impression of the possible role 